\title{
Pediatric Clinical CT Cases
}

\author{
Heba Kamal Weshahy* \\ Assistant Lecturer of Pediatrics and Pediatric Cardiology, National Heart Institute, Egypt
}

Submission: November 17, 2017; Published: December 01, 2017

*Corresponding author: Heba Kamal Weshahy, Assistant Lecturer of Pediatrics and Pediatric Cardiology, National Heart Institute, Egypt, Tel: +201060003667; Email: hebaweshahy@yahoo.com

\begin{abstract}
Five clinical pediatric CT cases; the first case has dysnea, respiratory distress, cardiomegaly and gallop. Echocardiography showed dilated left ventricle with impaired contractility EF $20 \%$, FS $10 \%$. CT angiography showed absent left main coronary artery, anomalous origin of the LCX and LAD by separate ostia from the left side of the main pulmonary artery, diffuse dilatation of the RCA, Many dilated inter-coronary collaterals (adult type of ALCAPA). The second case has dysnea, recurrent pneumonia, respiratory distress, cardiomegaly and gallop. Echocardiography demonstrated dilated left ventricle with impaired contractility EF $22 \%$, FS 10\%, suspected ALCAPA. CT revealed anomalous origin of the LAD from the left side of the main pulmonary artery, left circumflex arises from the left coronary sinus of Valsalva and runs its normal course, mild diffuse dilatation of the RCA (ALCAPA). The third case has 9 months old female, recurrent pneumonia, feeding difficulties, poor weight gain, cardiomegaly and accentuated S2. Echocardiography revealed dilated RV, severe TR, moderate sized secundum ASD and pulmonary hypertension. CT showed average sized main pulmonary artery continuous with its left branch, absent right pulmonary artery, indirect MAPCA supplying the right lung, diminished right lung volume. The forth case 20 months old female, dysnea, cyanosis, left upper limb weakness, and systolic murmur. Echocardiography showed TOF. CT showed average sized confluent main pulmonary artery and it's both branches, abnormal origin of the left subclavian artery from the left pulmonary artery, right sided aortic arch. The fifth case has 18 months old female, 6 months following surgical closure of VSD and epicardial pacemaker insertion, dysnea, respiratory distress, pansystolic murmur. Echocardiography revealed abnormal flow directed from the aorta to the RV, suspected ruptured sinus of Valsalva. CT showed residual VSD between the LVOT and RV cavity just below the Tricuspid valve.
\end{abstract}

\section{Introduction}

SComputerized Tomography CT Angiography of the heart and blood vessels could be considered now is an important tool for the diagnosis and management of congenital heart diseases whether before or after surgical or interventional management as well as follow up and detection of post-management complications. In the last two decades, computed tomography (CT) scan has emerged as valuable non-invasive cardiovascular diagnostic tool capable of producing informative pictures, providing unique anatomic and functional information not available by any other diagnostic modality currently available; as well as for the assessment of the anatomy of the extra-cardiac structures.

\section{Case Report 1 (Dilated Cardiomyopathy in a Four Years Old Girl)}

\section{Introduction}

Anomalous origin of the left coronary artery from the pulmonary artery (ALCAPA) syndrome, also known as BlandWhite-Garland syndrome, is a rare congenital abnormality that affects 1 of every 300,000 live births [1] and accounts for $0.25 \%$ $0.5 \%$ of all congenital heart defects [2]. It usually manifests as an

isolated defect, but in $5 \%$ of cases it may be associated with other cardiac anomalies such as atrial septal defect, ventricular septal defect, and aortic coarctation [3].

ALCAPAsyndrome results in the "coronary steal" phenomenon, in which a left-to-right shunt leads to abnormal left ventricular perfusion. ALCAPA syndrome is one of the most common causes of myocardial ischemia and infarction in children. If left untreated, up to $90 \%$ of patients with ALCAPA syndrome die within the 1st year of life [4]. In patients who live to adulthood, ALCAPA syndrome may cause myocardial infarction, left ventricular dysfunction and mitral regurgitation, or silent myocardial ischaemia, which can lead to sudden cardiac death. Early diagnosis and prompt surgical intervention with the aim of restoring a two-coronary-artery circulatory system have excellent results and lead to gradual myocardial recovery.

\section{Clinical picture}

By history; four years old female, presented by dysnea, growth delay and respiratory distress grade II to III, by examination; cardiomegaly and gallop was noted. 


\section{Echocardiography}

It revealed dilated cardiomyopathy, markedly dilated left ventricle with markedly impaired contractility Ejection Fraction $20 \%$, Fractional Shortening 10\%.

\section{CT angiography on the heart and blood vessels}

It revealed a case of dilated cardiomyopathy showing: Absent left main coronary artery, Anomalous origin of the Left Circumflex and Left Anterior Descending arteries by separate ostia from the left side of the main pulmonary artery, Diffuse dilatation of the Right Coronary Arteries, Many dilated inter-coronary collaterals. A picture of adult type of ALCAPA (Figure 1).

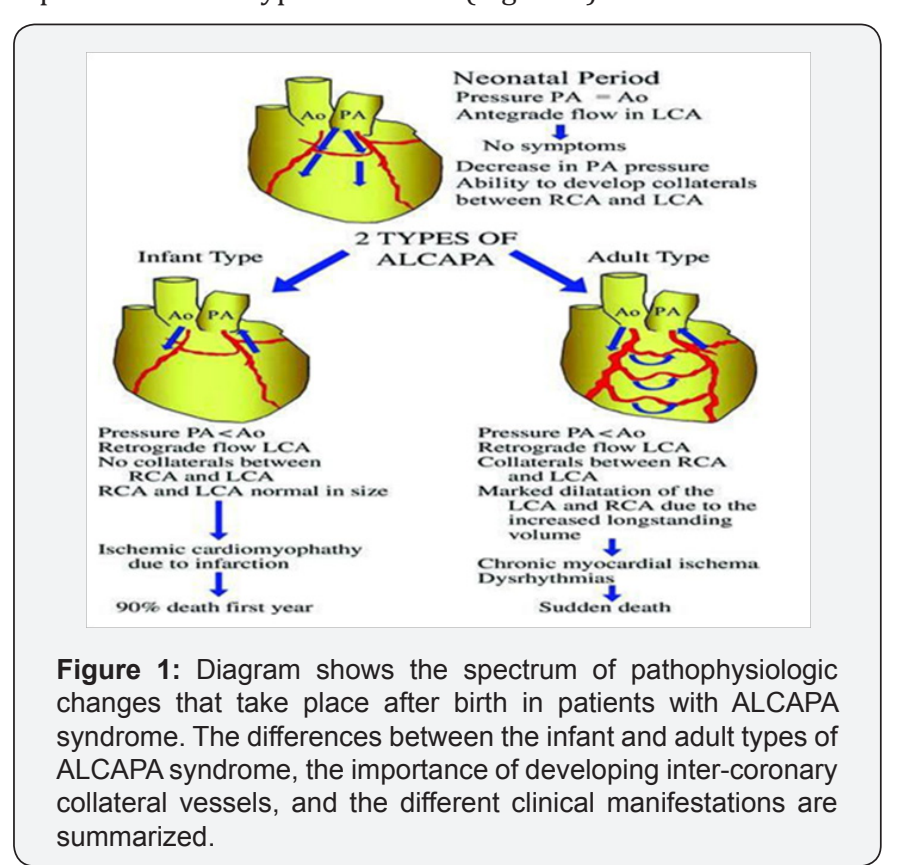

\section{Pathophysiology}

In fetal and early neonatal life, the origin of the left coronary artery (LCA) from the pulmonary artery is well tolerated because pulmonary arterial pressure equals systemic pressure, which leads to antegrade flow in both the anomalous LCA and the normal right coronary artery (RCA) [5].

Soon after birth, when pulmonary arterial pressure decreases, flow in the LCA decreases and then reverses, which leads to myocardial ischaemia and infarction. The extent of acquired collateral circulation between the RCA and LCA during the critical period, when pulmonary arterial pressure gradually decreases, determines the extent of myocardial ischaemia (Figure 1). Patients with well-established collateral vessels have the adult type of the disease, and those without collateral vessels have the infant type. Both types of the disease have different manifestations and outcomes.

Infant type: The onset of symptoms usually occurs about 8 weeks after birth. There is little or no coronary collateral development. When the reversal of flow in the LCA is established, a limited blood supply to the left ventricular myocardium leads to congestive heart failure and mitral insufficiency secondary to myocardial infarction [4,6]. The most important differential diagnosis in this age group is dilated cardiomyopathy [1]. Infants typically present with a failure to thrive, profuse sweating, dysnea, pallor, and atypical chest pain while eating or crying. Without surgical repair, rapid death ensues in up to $90 \%$ of patients within weeks or months of birth [4].

Adult type: As pressure decreases in the pulmonary circulation and as flow reverses in the LCA, the LCA fails to supply the myocardium and "drains" fully oxygenated blood into the main pulmonary artery. Thus, there is preferential blood flow into the low-pressure pulmonary circulation rather than into the highresistance myocardial circulation. This left to-right shunt is known as the steal phenomenon. To survive beyond infancy, patients with ALCAPA syndrome develop significant collateral circulation from the RCA to the LCA. However, often it is not sufficient to supply the left ventricle, especially in the sub-endocardial region; chronic left ventricular sub-endocardial ischaemia ensues. As a result, patients may develop malignant ventricular dysrhythmias. These patients are at risk for sudden cardiac death, which occurs in $80 \%-90 \%$ of cases [7-11]. Patients may be asymptomatic, or they may present with mitral insufficiency, ischemic cardiomyopathy, or malignant dysrhythmias, which lead to sudden death [4] (Figure 2-8).
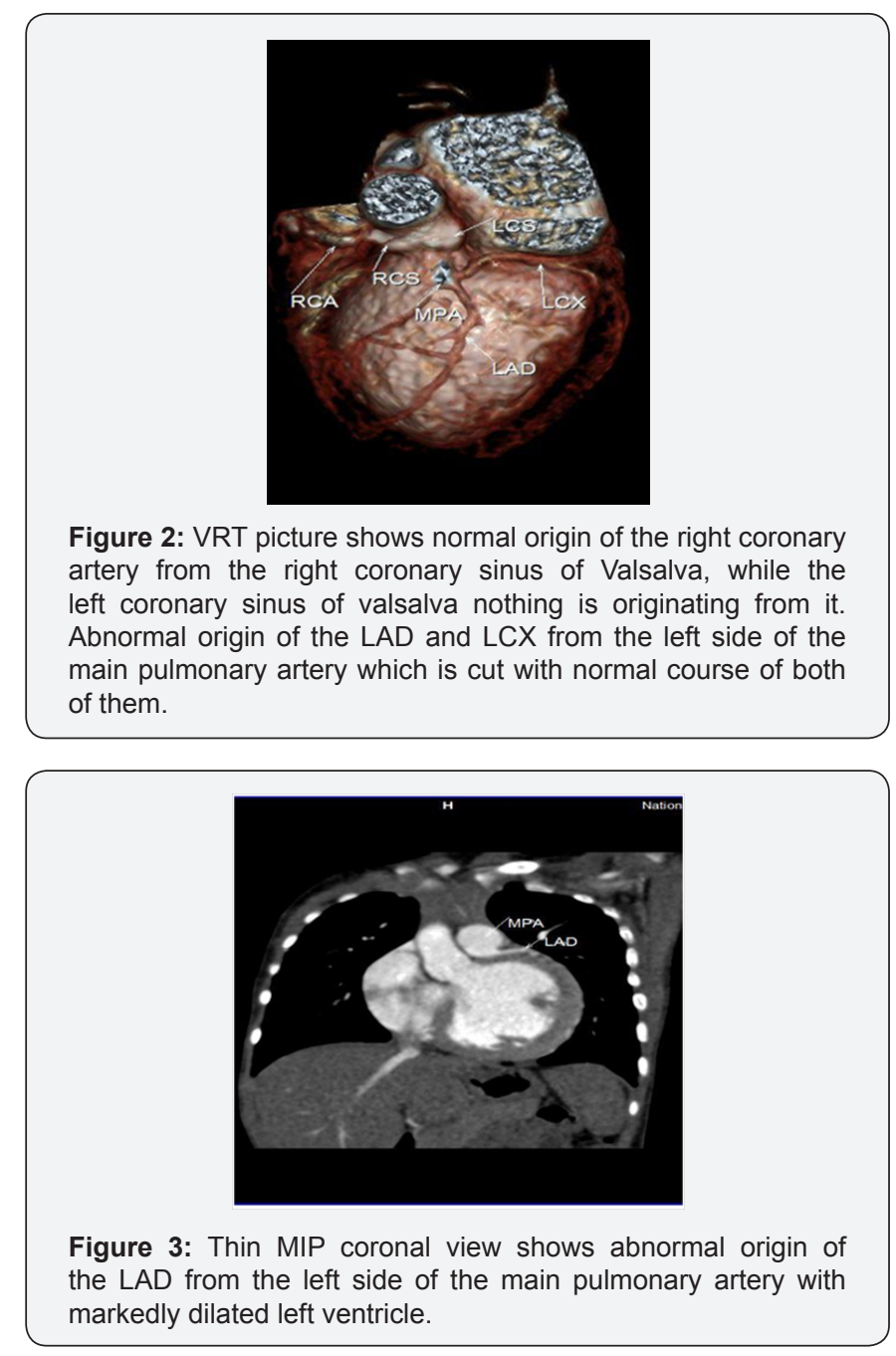


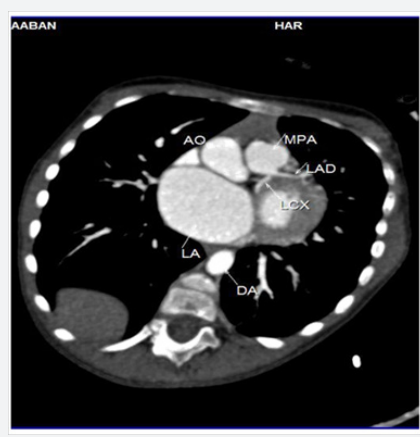

Figure 4: Thin MIP axial view shows abnormal origin of the LAD and LCX from the left side of the main pulmonary artery by separate ostia.

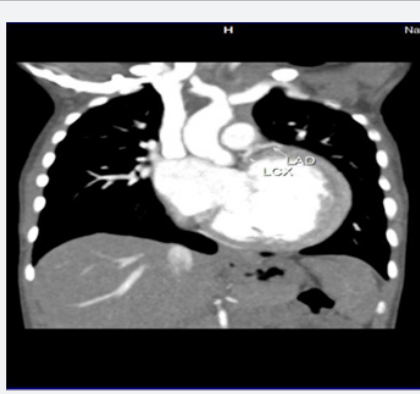

Figure 5: Thin MIP coronal view shows abnormal origin of the LAD and LCX from the left side of the main pulmonary artery by separate ostia, with markedly dilated left ventricle.

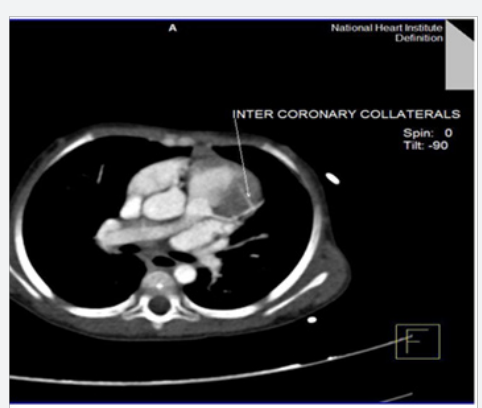

Figure 6: MPR axial view shows abnormal origin of the LAD from the left side of the main pulmonary artery at the right ventricular outflow tract, with small inter-coronary collateral.

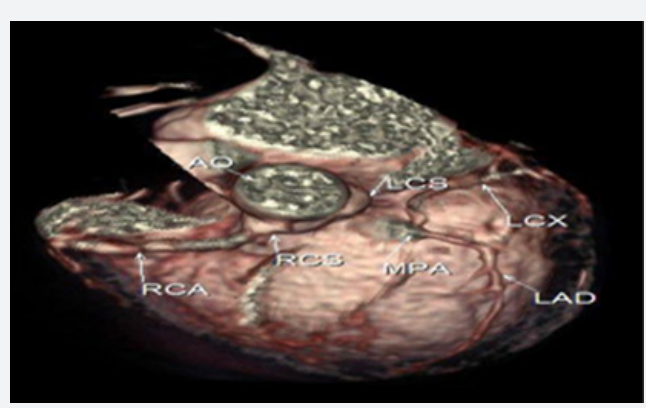

Figure 7: VRT picture shows normal origin of the right coronary artery from the right coronary sinus of valsalva, while the left coronary sinus of valsalva nothing is originating from it. Abnormal origin of the LAD and LCX from the left side of the main pulmonary artery which is cut with normal course of both of them.

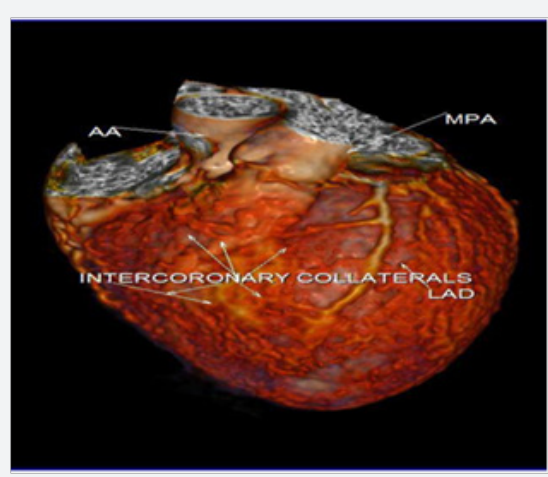

Figure 8: VRT picture shows multiple inter-coronary collaterals between the right and left coronary arteries.

Case Report 2 (Dilated Cardiomyopathy in Ten Months Old Girl)

\section{Clinical picture}

By history; ten months old female, presented by dysnea, recurrent chest infections, growth delay and respiratory distress grade II to III, cardiomegaly and gallop by examination. It revealed dilated cardiomyopathy, markedly dilated left ventricle with markedly impaired contractility EF $22 \%$, FS $10 \%$, suspected ALCAPA.

\section{CT angiography on the heart and blood vessels}

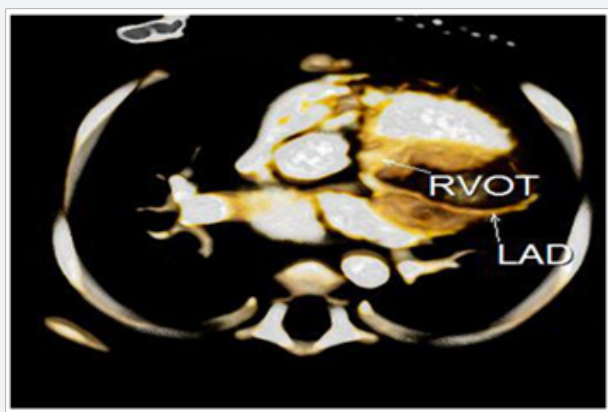

Figure 9: Thin VRT axial view shows abnormal origin of the left anterior descending coronary artery from the left side of the main pulmonary artery at the level of the right ventricular outflow tract.

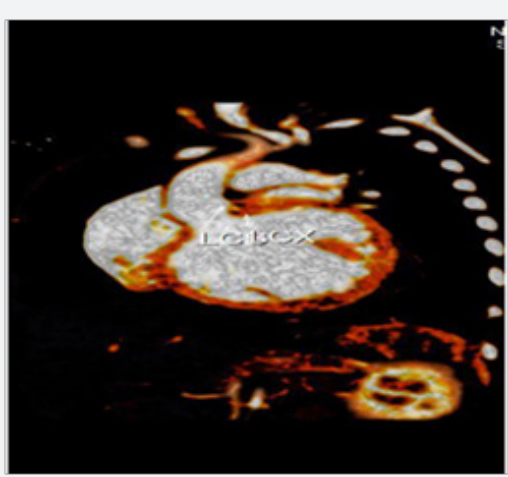

Figure 10: Thin VRT coronal view shows normal origin of the left circumflex coronary artery from the left coronary sinus of valsalva and runs its normal course, with marked dilatation of the left ventricle. 
It revealed a case of dilated cardiomyopathy showing; Anomalous origin of the LAD by a separate ostium from the left side of the main pulmonary artery, while the left circumflex arises from the left coronary sinus of valsalva and runs its normal course, with Mild diffuse dilatation of the RCA (A picture of ALCAPA) (Figure 9-12).

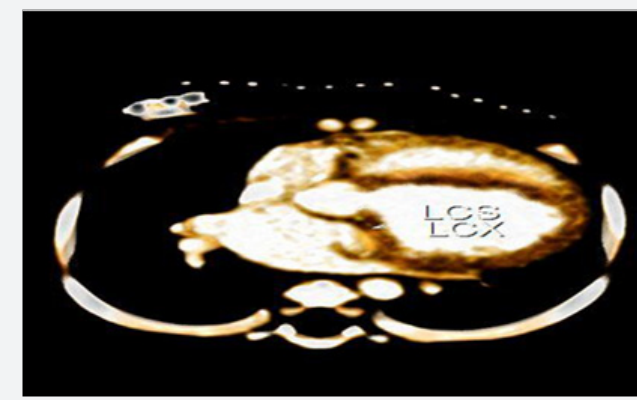

Figure 11: Thin VRT axial view shows normal origin of the left circumflex coronary artery from the left coronary sinus of valsalva and runs its normal course in the left atrioventricular groove, with marked dilatation of the left ventricle.

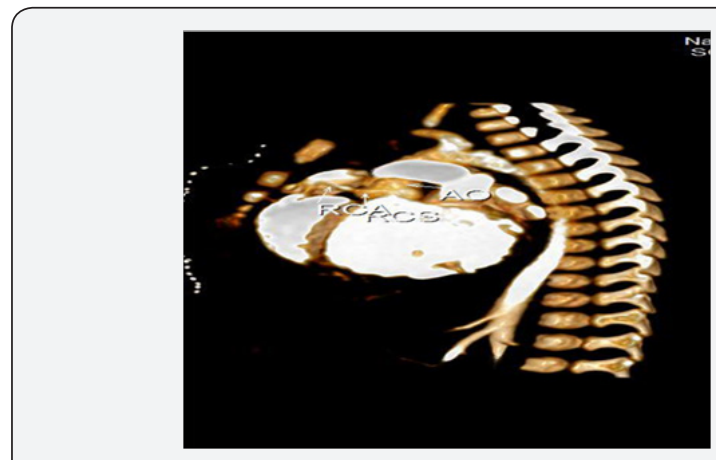

Figure 12: Thin VRT saggital view shows normal origin of the right coronary artery from the right coronary sinus of valsalva and runs its normal course in the right atrioventricular groove.

\section{Case Report 3 (ASD with Severe Pulmonary Hypertension)}

\section{Introduction}

Isolated absence of right pulmonary artery is a rare congenital lesion with a diverse clinical presentation. This defect was first reported by Fraentzel in 1868. Pool et al. [12] studied 78 cases with absence of either of the branch pulmonary arteries and found 32 cases $(\sim 40 \%)$ without any additional cardiac lesion. Fifty-six patients in their series had additional structural cardiac problems such as Tetralogy of Fallout (21\%), patent ductus arteriosus (PDA; 14\%) and septal defects (9\%). Isolated absence of RPA was associated with pulmonary hypertension in $19-44 \%$ of the patients in different case series [13]. Isolated absence of RPA frequently presents in infancy with PHT and congestive cardiac failure [14]. A high index of suspicion is required to diagnose this condition in infancy [15].

\section{Clinical picture}

Nine months old female presenting by recurrent chest infections, respiratory distress, feeding difficulties and poor weight gain, cardiomegaly and accentuated second heart sound by examination.

\section{Echocardiography}

Dilated right ventricle, severe Tricuspid regurgitation, moderate sized secundum atrial septal defect and severe pulmonary hypertension.

\section{CT angiography on the heart and blood vessels}

It revealed a case of moderate sized secundum atrial septal defect showing: Average sized main pulmonary artery continuous with its left branch, absent right pulmonary artery, indirect major aorto-pulmonary collateral originating from the brachiocephalic artery and supplying the right lung, diminished right lung volume with minimal pleural effusion.

\section{Discussion}

Two types of presentations are described. The first presentation is the one seen in infants, where they usually present with congestive cardiac failure and PHT [16,17]. The other presentation is in older patients, who usually do not develop pulmonary hypertension and do not have manifest heart failure. They present with exercise intolerance (18-40\%), hemoptysis (20\%) or are incidentally detected during chest radiography [18]. The diagnosis of isolated absence of RPA is based on history, clinical evaluation and imaging. A high index of suspicion is needed to make the diagnosis. In infancy, the signs can be subtle and can be easily missed $[14,15]$. The electrocardiogram is usually normal in patients with uncomplicated isolated absence of pulmonary artery (without PHT), whereas it shows right ventricular dominance in cases associated with PHT [16]. Chest X-ray may show an absent hilar shadow, absence of the left or RPA, reduction of pulmonary vascular markings on the right side ( $\sim 60 \%$ cases), a small hemithorax and intercostal bone space, shrunken affected lung and a shift of the mediastinal structures to the affected side with contralateral lung hyperinflation [14,19]. A cardiac MDCT scan and magnetic resonance imaging (MRI) can confirm the diagnosis and delineate the pulmonary artery anatomy along with delineating MAPCA if present.

\section{Conclusion}

Any infant with unexplained PHT should be thoroughly evaluated for the possibility of isolated unilateral absence of pulmonary artery (UAPA). Differential vascularity on the chest $\mathrm{X}$-ray may often be a clue for the diagnosis. Isolated absence of RPA is a rare entity. In infancy, it presents with respiratory distress and severe PHT. A high index of suspicion is needed to diagnose the entity. Differential vascularity in the chest X-ray can give a clue. MDCT scan and MRI can confirm the echocardiographic diagnosis and delineate the pulmonary artery anatomy. The surgical 
treatment plan depends on the presence of a good-sized hilar pulmonary artery and the presence of MAPCA. Early surgical or hybrid intervention may improve survival. Medical management includes symptomatic treatment for congestive cardiac failure and long-term pulmonary vasodilator for PHT. Infants with severe PHT are difficult to treat and have an unfavorable outcome (Figure 13-17).

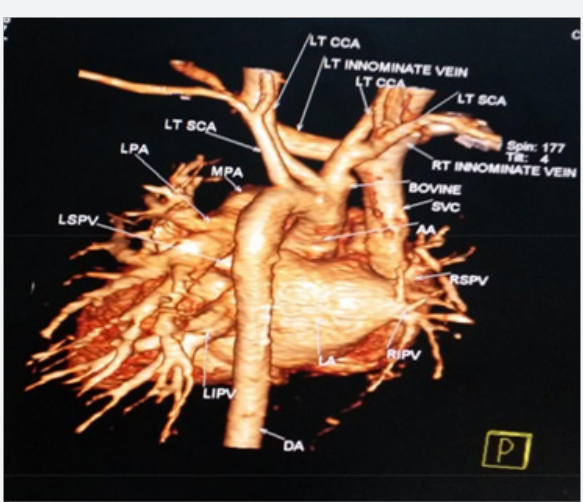

Figure 13: 3D VRT picture, posterior view shows absence of the right pulmonary artery, small indirect collateral originating from the brachiocephalic artery and supplying the right lung.

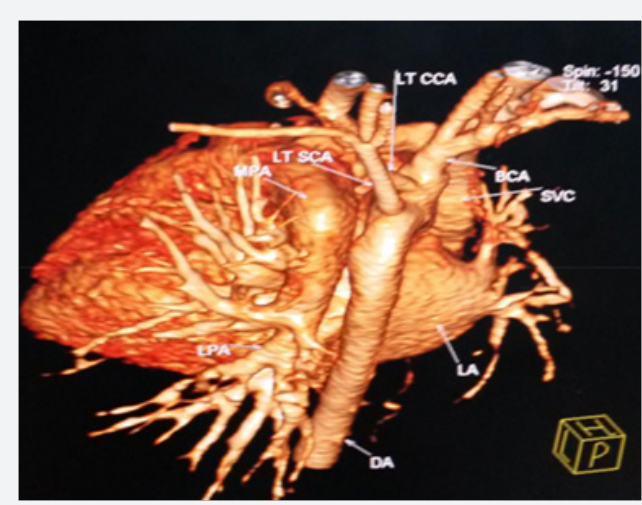

Figure 14: 3D VRT picture, postrosuperior view shows absence of the right pulmonary artery, small indirect collateral originating from the brachiocephalic artery and supplying the right lung.

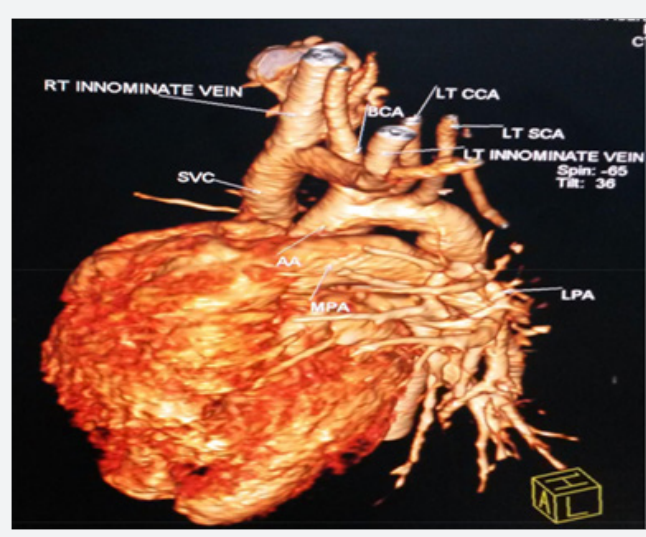

Figure 15: 3D VRT picture, lateral view shows absence of the right pulmonary artery.
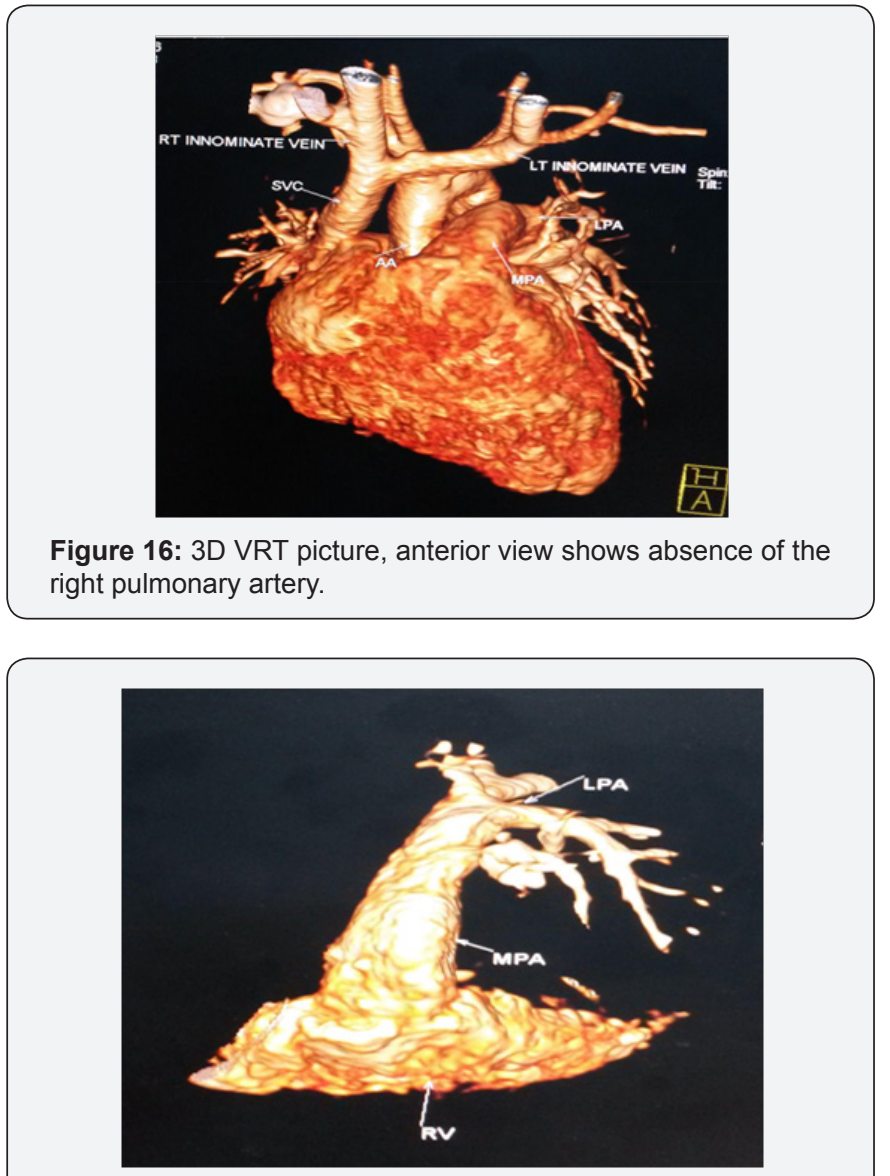

Figure 17: 3D VRT picture for the isolated pulmonary tree, anterior view shows absence of the right pulmonary artery.

Case Report 4 (Tetralogy of Fallot with Upper Limb Weakness)

\section{Clinical picture}

Twenty months old female, presented by dysnea, cyanosis and growth delay, weakness of the left upper limb (reported by the parents; for which receiving physiotherapy), right ventricular enlargement, systolic murmur, unequal radial pulsations, intact femoral pulses, blood pressure was 91/62 in right upper limb and $61 / 33$ in the left upper limb with left upper limb weakness, hypotonia and hyporeflexia by examination.

\section{Echocardiography}

It revealed tetralogy of fallout with good size of pulmonary arteries.

\section{CT angiography}

It revealed: A case of tetralogy of Fallout showing: average sized confluent main pulmonary artery and its branches, McGoon's ratio 2.2/1, bifurcational stenosis of the left and right pulmonary arteries, right sided aortic arch with mirror image branches, abnormal origin of the left subclavian artery from the left pulmonary artery at its junction with the main pulmonary artery. 


\section{Theoretical background}

Definition: Left subclavian artery isolation is an uncommon anomaly in which the right sided aortic arch is associated with anomalous origin of the LSCA from the pulmonary artery via ductus arteriosus or ligamentum arteriosum without communication with the aorta Weinberg et al. [13].

Embryology: The development of the aortic arch and its branches occurs during the third week of gestation. A common arterial trunk arises from the primitive heart and divides into six paired aortic arches that fuse and form bilateral dorsal aortae which, in turn, fuse caudally into the descending aorta. The persistence or regression of these arches may lead to various aortic arch anomalies Edwards et al. [6]. Edwards' embryologic model of aortic arch malformation explains this LSCA isolation by the interruption of the left aortic arch at two locations: between the left carotid and subclavian arteries, or between the ductus arteriosus and the left dorsal aortic root Edwards et al. [6].

Associated anomalies: The isolation of the LSCA is commonly associated with 22q11 deletion and congenital heart diseases e.g. Tetralogy of Fallot, Double-outlet right ventricle and D-transposition of the great arteries [20].

Clinical presentations: The condition is usually asymptomatic and discovered during the evaluation of the associated cardiac anomalies or when reduced blood pressure is detected in the left arm. Left arm ischaemia, including pain, weakness, coldness, and reduced limb length, may be present in about $15 \%$ of cases (cases not associated with patent ductus arteriosus [12]).

Treatment: surgical reimplantation of the left subclavian artery and ligation or device closure of the PDA if present.

Conclusion: Anomalies of the aortic arch and its branches should be considered in cases of unequal radial pulse, unequal blood pressure in arms, upper limb weakness or ischaemia [12,16-23] (Figure 18-22).

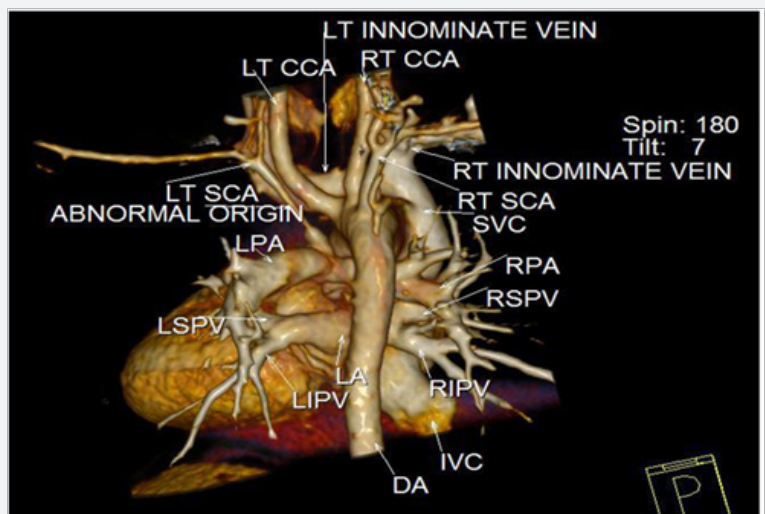

Figure 18: 3D VRT picture, posterior view shows right sided aortic arch with abnormal origin of the left subclavian artery from the left pulmonary artery.

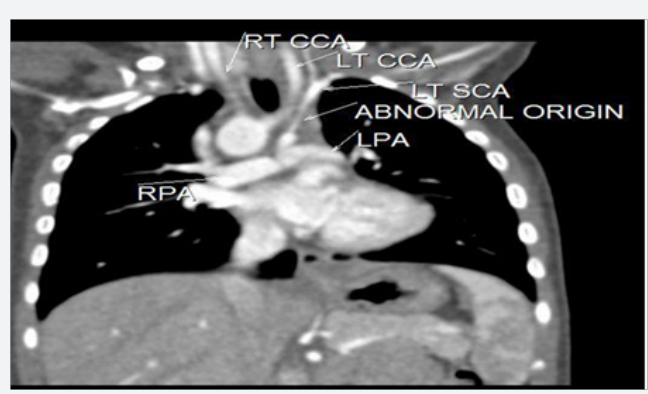

Figure 19: Thin MIP coronal view shows abnormal origin of the left subclavian artery from the left pulmonary artery.

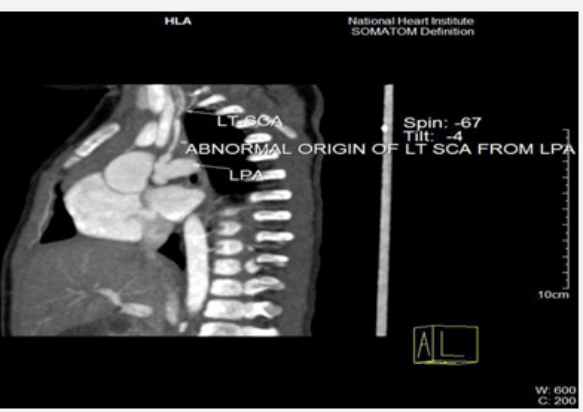

Figure 20: Thin MIP saggital view shows abnormal origin of the left subclavian artery from the left pulmonary artery.

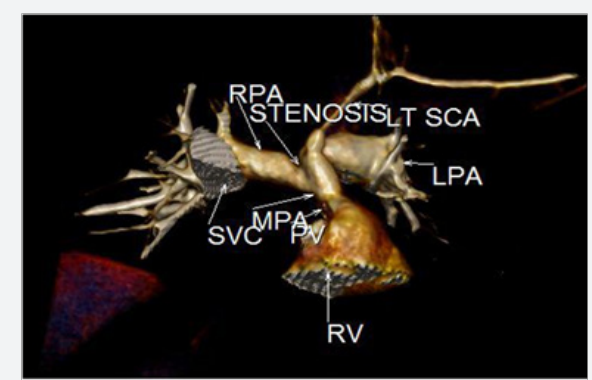

Figure 21: 3D VRT picture for isolated pulmonary tree shows abnormal origin of the left subclavian artery from the junction between the main pulmonary artery and the left pulmonary artery with mild proximal stenosis of the right pulmonary artery.

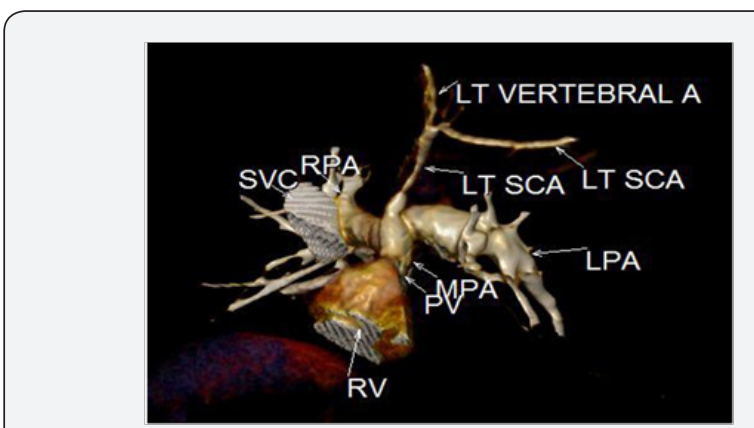

Figure 22: 3D VRT picture for isolated pulmonary tree shows abnormal origin of the left subclavian artery from the junction between the main pulmonary artery and the left pulmonary artery with mild proximal stenosis of the left pulmonary artery. 


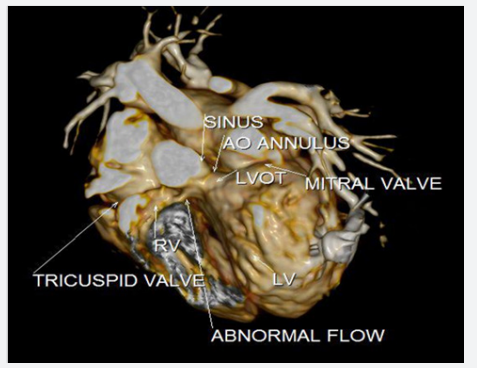

Figure 23: 3D VRT picture showing residual ventricular septal defect between the left ventricular outflow tract and the right ventricular cavity just below the Tricuspid valve with normal aortic annulus, normal coronary sinuses of valsalva and normal coronary arteries.

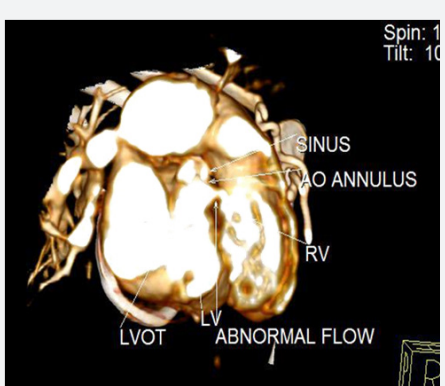

Figure 24: 3D VRT picture showing residual ventricular septal defect between the left ventricular outflow tract and the right ventricular cavity just below the Tricuspid valve with normal aortic annulus, normal coronary sinuses of valsalva and normal coronary arteries.

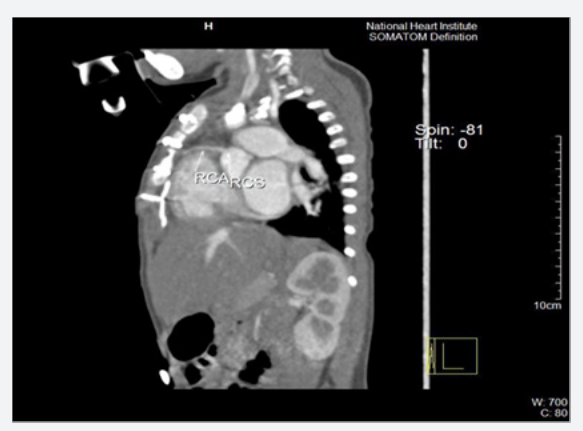

Figure 25: Thin MIP saggital view showing median sternotomy sutures, normal origin and course of the right coronary artery.

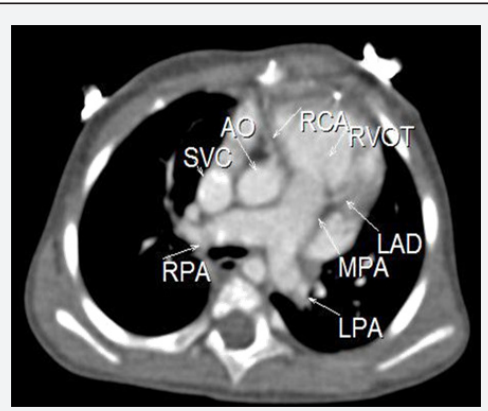

Figure 26: Thin MIP axial view showing normal origin and course of the coronary artery and left anterior descending artery.

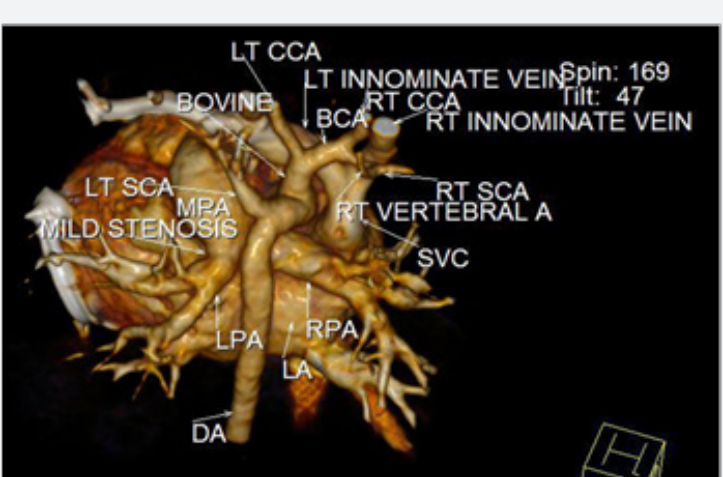

Figure 27: 3D VRT picture showing mild proximal stenosis of the left pulmonary artery and epicardial pacemaker.

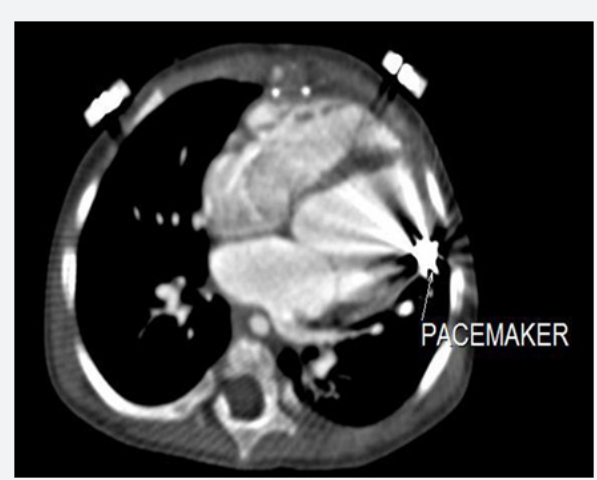

Figure 28: 3D VRT picture showing epicardial pacemaker surgically implanted.

\section{Case Report 5 (Postoperative Residual VSD)}

\section{Clinical picture}

Eighteen months old female, presented 6 months following surgical closure of ventricular septal defect followed by surgical epicardial pacemaker implantation by dysnea and respiratory distress grade II to III, harsh pansysteolic murmur over the left parasternal area by examination.

\section{Echocardiography}

It revealed abnormal flow directed from the aorta to the right ventricle, suspected ruptured sinus of valsalva.

\section{CT angiography on the heart and blood vessels}

It revealed status post surgical VSD closure and epicardial pacemaker insertion, showing: Residual ventricular septal defect between the left ventricular outflow tract and the right ventricular cavity just below the Tricuspid valve, with normal aortic annulus, normal coronary sinuses of valsalva and normal coronary arteries with Mild proximal stenosis of the left pulmonary artery (Figure 23-28) [24-30].

\section{References}

1. Khatami AD, Mavroudis C, Backer CL (2002) Anomalous origin of the left coronary artery from the pulmonary artery: collective review of surgical therapy. Ann Thorac Surg 74: 946-955. 
2. Pfannschmidt J, Ruskowski H, de Vivie ER (1992) Das Bland-WhiteGarland syndrome: clinical aspects, diagnosis, therapy [in German]. Klin Padiatr 204(5): 328-334.

3. Takimura CK, Nakamoto A, Hotta VT, Campos MF, Malamo M, et al. (2002) Anomalous origin of the left coronary artery from the pulmonary artery: report of an adult case. Arq Bras Cardiol 78(3): 309-314.

4. Wesselhoeft H, Fawcett JS, Johnson AL (1968) Anomalous origin of the left coronary artery from the pulmonary trunk: its clinical spectrum, pathology and pathophysiology, based on a review of 140 cases with seven further cases. Circulation 38: 403-425.

5. Schwerzmann M, Salehian O, Elliot T, Merchant N, Siu SC, et al. (2004) Anomalous origin of the left coronary artery from the main pulmonary artery in adults-coronary collateralization at its best. Circulation 110: e511-e513.

6. Edwards JE (1964) The direction of blood flow in coronary arteries arising from the pulmonary trunk. Circulation 29: 163-166.

7. Moodie DS, Fyfe D, Gill CC (1983) Anomalous origin of the left coronary artery from the pulmonary artery (Bland-White-Garland syndrome) in adult patients: long-term follow-up after surgery. Am Heart J 106(2): 381-388.

8. Meskishvili VA, Berger F, Weng Y, Lange PE, Hetzer R (1995) Anomalous origin of the left coronary artery from the pulmonary artery in adults. J Card Surg 10(14 Pt 1): 309-315.

9. Berdjis F, Takahashi M, Wells WJ, Stiles QR, Lindesmith GG (1994) Anomalous left coronary artery from the pulmonary artery: significance of intercoronary collaterals. J Thorac Cardiovasc Surg 108(1): 17-20.

10. Fernandes ED, Kadivar H, Hallman GL, Reul GJ, Ott DA, et al. (1992) Congenital malformations of the coronary arteries: the Texas Heart Institute experience. Ann Thorac Surg 54(4): 732-740.

11. Arciniegas E, Farooki ZQ Hakimi M, Green EW (1980) Management of anomalous left coronary artery from the pulmonary artery. Circulation 62(2 Pt 2): I180-I189.

12. Pool PE, Vogel JK, Blount SG (1962) Congenital unilateral absence of a pulmonary artery. The importance of flow in pulmonary hypertension. Am J Cardiol 10(5): 706-732.

13. Weinberg PM, Natarajan S, Rogers LS (2013) Aortic arch and vascular anomalies.

14. Uchino A, Saito N, Okada Y, Kozawa E, Nishi N, et al. (2013) Variation of the origin of the left common carotid artery diagnosed by CT angiography. Surg Radiol Anat 35(4): 339-342.

15. Shakibi JG, Rastan H, Nazarian I, Paydar M, Aryanpour I, et al. (1978) Isolated unilateral absence of the pulmonary artery. Review of the world literature and guidelines for surgical repair. Jpn Heart J 19(3): 439-451.

16. Frentzel 0 (1868) Ein Fall von anormer Communicationder Aorta mit der Arteria Pulmonalis. Virchow's Arch path Anat 43: 420-422.
17. Bouros D, Pare P, Panagou P, Tsintiris K, Siafakas N (1995) The varied manifestation of pulmonary artery agenesis in adulthood. Chest 108(3): 670-676.

18. Ten Harkel AD, Blom NA, Ottenkamp J (2002) Isolated unilateral absence of a pulmonary artery. Chest 122(4): 1471-1477.

19. Bahler RC, Carson P, Traks E, Levene A, Gillespie D (1969) Absent right pulmonary artery: Problems in diagnosis and management. Am J Med 46(1): 64-71.

20. Apostolopoulou SC, Kelekis NL, Brountzos EN, Rammos S, Kelekis DA (2002) "Absent" pulmonary artery in one adult and five pediatric patients: imaging, embryology, and therapeutic implications. AJR Am J Roentgenol 179(5): 1253-1260.

21. Cucci CE, Doyle EF, Lewis EW (1964) Absence of a primary division of the pulmonary trunk: an ontogenetic theory. Circulation 29: 124-131.

22. Haworth SG, de Leval M, Macartney FJ (1981) Hypoperfusion and hyperperfusion in the immature lung. Pulmonary arterial development following ligation of the left pulmonary artery in the newborn pig. J Thorac Cardiovasc Surg 82(2): 281-292.

23. Haworth SG, McKenzie SA, Fitzpatrick ML (1981) Alveolar development after ligation of left pulmonary artery in newborn pig: clinical relevance to unilateral pulmonary artery. Thorax 36(12): 936-943.

24. Rubin E, Strauss L (1960) Congenital absence of the right pulmonary artery. Report of a case in a five month old infant, with suggestive evidence of unilateral pulmonary hypertension. Am J Cardiol 6(2): 344-350.

25. King SB, Aversano T, Ballard WL, Beekman RH, Cowley MJ, et al. (2007) ACCF/AHA/SCAI 2007 update of the clinical competence statement on cardiac interventional procedures: a report of the American college of cardiology foundation/American heart association/American college of physicians task force on clinical competence and training (writing committee to update the 1998 clinical competence statement on recommendations for the assessment and maintenance of proficiency in coronary interventional procedures). J Am Coll Cardiol 50(1): 82108.

26. Mosieri J, Chintala K, Delius RE, Walters HL, Hakimi M (2004) Abnormal origin of the right subclavian artery from the right pulmonary artery in a patient with D-transposition of the great vessels and left juxtaposition of the right atrial appendage an unusual anatomical variant. J Card Surg 19(1): 41-44.

27. Pena E, Nguyen ET, Merchant N, Dennie C (2009) ALCAPA syndrome not just a pediatric disease. Radiographics 29(2): 553-565.

28. Yua J, Singh R, Halpern EJ, Fischman D (2011) Anomalous origin of the left coronary artery from the pulmonary artery.

29. Atik E, Tanamati C, Kajita L, Babero-Marcial M (2006) Unilateral pulmonary artery agenesis.

30. Deutsch MA, Thieme SF, Hinterseer M, Johnson RCT, Pfosser A, et al (2010) Adult presentation of combined unilateral atresia of the right proximal pulmonary artery and left patent ductus arteriosus: Case report and embryological considerations. International journal of cardiology 141(1): e4-e7. 
CC) This work is licensed under Creative CC) DOI: 10.19080/JOCCT.2017.08.555740

\section{Your next submission with Juniper Publishers} will reach you the below assets

- Quality Editorial service

- Swift Peer Review

- Reprints availability

- E-prints Service

- Manuscript Podcast for convenient understanding

- Global attainment for your research

- Manuscript accessibility in different formats ( Pdf, E-pub, Full Text, Audio)

- Unceasing customer service

Track the below URL for one-step submission https://juniperpublishers.com/online-submission.php 